\title{
Near-real-time volcanic cloud monitoring: insights into global explosive volcanic eruptive activity through analysis of Volcanic Ash Advisories
}

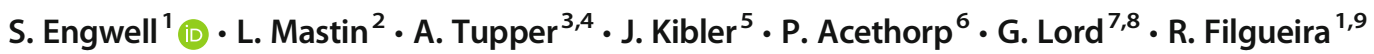

Received: 29 April 2020 / Accepted: 29 October 2020 / Published online: 21 January 2021

(C) The Author(s) 2020

\begin{abstract}
Understanding the location, intensity, and likely duration of volcanic hazards is key to reducing risk from volcanic eruptions. Here, we use a novel near-real-time dataset comprising Volcanic Ash Advisories (VAAs) issued over 10 years to investigate global rates and durations of explosive volcanic activity. The VAAs were collected from the nine Volcanic Ash Advisory Centres (VAACs) worldwide. Information extracted allowed analysis of the frequency and type of explosive behaviour, including analysis of key eruption source parameters (ESPs) such as volcanic cloud height and duration. The results reflect changes in the VAA reporting process, data sources, and volcanic activity through time. The data show an increase in the number of VAAs issued since 2015 that cannot be directly correlated to an increase in volcanic activity. Instead, many represent increased observations, including improved capability to detect low- to mid-level volcanic clouds (FL101-FL200, 3-6 km asl), by higher temporal, spatial, and spectral resolution satellite sensors. Comparison of ESP data extracted from the VAAs with the Mastin et al. (J Volcanol Geotherm Res 186:10-21, 2009a) database shows that traditional assumptions used in the classification of volcanoes could be much simplified for operational use. The analysis highlights the VAA data as an exceptional resource documenting global volcanic activity on timescales that complement more widely used eruption datasets.
\end{abstract}

Keywords Explosive eruptions · Volcanic Ash Advisory Centres (VAACs) · Volcanic ash hazard · Volcanic record

\section{Introduction}

Operational forecasting of volcanic ash dispersal in the atmosphere is underpinned by near-real-time reports that provide a valuable untapped data resource. Here, we use a novel dataset comprising Volcanic Ash Advisories (VAAs), issued over 10 years by the world's nine Volcanic Ash Advisory

Editorial responsibility: C.E.Gregg

S. Engwell

sameng@bgs.ac.uk

1 British Geological Survey, The Lyell Centre, Research Avenue South, Edinburgh, UK

2 U.S. Geological Survey, Cascades Volcano Observatory, 1300 SE Cardinal Court Bldg. 10, Vancouver, WA, USA

3 Bureau of Meteorology, 700 Collins Street, Docklands Vic, Melbourne, Australia

4 Natural Hazards Consulting, Melbourne, Australia
Centres (VAACs), to investigate global rates and durations of explosive volcanic activity and inform understanding of characteristics of this activity, particularly with regard to cloud height. All acronyms used herein are defined in Appendix located at the end of the paper.

Explosive volcanic eruption frequency trends have traditionally been analysed from deposits (Walker 1973; Pyle
5 Washington Volcanic Ash Advisory Center NOAA/NESDIS/ Satellite Analysis Branch, 5830 University Research Court, College Park, MD, USA

6 Civil Aviation Authority of New Zealand, 55 Featherston Street, PO Box 3555, Wellington, New Zealand

7 Department of Mathematics, IMAPP, Radboud University, Nijmegen, The Netherlands

8 Maxwell Institute, Department of Mathematics, MACS, Heriot Watt University, Edinburgh, UK

9 Edinburgh Parallel Computing Centre, University of Edinburgh, Edinburgh, UK 
1989; Mahony et al. 2016) and direct observations. This information is documented in databases such as the Smithsonian Institution Volcanoes of the World database (Siebert et al. 2010; Global Volcanism Program 2013) which contains information from the published record along with reports from State Volcano Observatories (SVOs), the LaMEVE (Large Magnitude Explosive Volcanic Eruptions) database (Crosweller et al. 2012) that comprises published information on large magnitude explosive eruptions, and the Icelandic Catalogue of Volcanoes (icelandicvolcanoes.is), a national database containing information on eruptive activity in Iceland. These databases characterise volcanic activity at an individual volcano and at a global level (Brown et al. 2015) and are used to anticipate future eruptive hazard, assuming that future behaviour (e.g. effusive or explosive and magnitude) will be similar to past behaviour (Sheldrake and Caricchi 2017). Such databases and studies focus on hazard and ash on the ground and have provided the basis for the development of probabilistic methodologies for assessing regional ash fall hazard (Jenkins et al. 2012).

Comparatively fewer datasets and studies focus specifically on hazard and risk to aviation from ash in the atmosphere (Guffanti et al. 2008; Guffanti and Tupper 2015; Lechner et al. 2017). The nature of atmospheric transport of volcanic ash, commonly over regional to global scales (for example the 2011 Cordon Caulle eruption; Collini et al. 2013), means that the assessment of ash hazard, and consequently risk to aviation, requires global datasets. One resource aimed at informing on ash hazard in the atmosphere is the eruption source parameter (ESP) database of Mastin et al. (2009a), which provides information required for forecasting atmospheric ash hazard associated with eruptive volcanic events through the initiation of volcanic-ash-transport-anddispersion models. While the Mastin et al. (2009a) database was produced with the ash aviation community in mind, it does not describe trends in volcanic activity or active volcanic behaviour. In this paper, we present VAAs as a potential resource to fill this data gap.

Observations are key for any assessment and forecast of volcanic hazard, whether on the ground or in the atmosphere. For ash in the atmosphere, observations come from a wide range of institutions and instruments. SVOs are crucial for providing ground observations in real-time. These observations include activity type (i.e. effusive or explosive) and intensity, and more specifically for the ash aviation issue, emission type (i.e. water vapour, gas, or ash), and observed cloud height. Such observations may be made directly by a local observatory or through analysis of webcam or radar imagery. Eruptive information is typically published in observatory reports and made available to the appropriate VAAC through the Volcanic Observatory Notice for Aviation (VONA) messages.

Satellite sensors are crucial tools for identifying and observing volcanic eruptions and ash in the atmosphere. The last 10 years has seen a major improvement in satellite sensor technology and coverage. With these improvements, the temporal resolution of observations has increased, meaning that there is now much more data for an eruptive event than would have been available even decades ago. New-generation geostationary satellites such as HIMAWARI-8 (Bessho et al. 2016), which launched in October 2014, with coverage over the Western and Central Pacific, image resolution down to $500 \mathrm{~m}$ for visible and $2 \mathrm{~km}$ for infrared imagery, and refresh frequencies up to $2.5 \mathrm{~min}$, enable detection of much smaller volcanic clouds than earlier counterparts. GOES-16 and GOES-17 satellites (GOES-R Program/ Code 410 2020) with refresh frequencies of between $30 \mathrm{~s}$ and 1 minute were launched respectively in November 2016 and March 2018 and cover the Americas, Eastern and Central Atlantic, and Eastern Pacific. These new satellites use the thermal infrared brightness temperature difference method (Prata 1989a, b), or 'true colour' satellite techniques to detect volcanic ash, with increased resolution and refresh frequencies, enabling better distinction from meteorological cloud. The increased detection capability of these new-generation satellites is supplemented by algorithms, such as the VOLcanic Cloud Analysis Toolkit (VOLCAT) (Pavolonis et al. 2018) and the Support to Aviation Control Service (SACS) system (Brenot et al. 2014) that scan satellite data and automatically detect emergent eruptive activity and notify of volcanic ash and $\mathrm{SO}_{2}$ in the atmosphere. Despite these improvements, there remain areas without satellite coverage on the frequency required to actively monitor volcanic activity globally. In addition, volcanic clouds are still often obscured by meteorological clouds making ground observations from SVO essential.

The increasingly large amounts of data describing global explosive volcanic activity produced by SVOs and VAACs pose both limitations and opportunities. Development of methods for presentation and analysis of datasets is required to fully capitalise on increased data availability. Information can be difficult to extract in a clear and consistent way from the many resources. As an example, there are more than seventy SVOs globally (World Organization of Volcano Observatories; http:/www.wovo.org/observatories/), each with their own methods of collection and communication of eruption information (Pallister et al. 2019). The collection of ash cloud information from satellite information requires access to satellite imagery and a number of assumptions for estimating ash cloud characteristics such as height. These analyses are time-consuming when considering global scales. In comparison, the information within VAAs, which draw on a wide range of observation sources, are easily accessed and analysed due to their consistent format. While SVO records and post-event analyses can contain additional and higher quality information about particular eruptions, the international repository of VAAs is the only near-real-time archive of global explosive volcanism, and it represents an enormously 
valuable resource. In addition, VAAs cover a number of volcanoes that are either not formally or only poorly monitored, providing a more representative record of global volcanic activity where ground observations from SVOs are not available.

Here, we examine 10 years of global explosive volcanic activity, from 1 January 2009 to 1 January 2019, through the information contained within VAAs. The VAAs are a mechanism of risk communication, issued in near-real-time in response to explosive volcanic events, to communicate the presence of volcanic ash in the atmosphere to the commercial aviation sector and other groups such as Meteorological Watch Offices (MWO) and SVOs. These VAAs contain a comprehensive record of the height, duration, and location of volcanic ash emissions in the atmosphere, allowing quantitative investigation of behaviour at frequently active volcanoes (e.g. Anatahan, Guffanti et al. 2005; Sinabung, Pallister et al. 2018; Fuego, Naismith et al. 2019), comparison among different geographical regions, and global analysis of explosive activity. We use this information to investigate the recent range of eruptive characteristics, in particular cloud height and duration, exhibited during explosive ash-producing events at a volcano and assess the categories assigned in the Mastin et al. (2009a) Eruption Source Parameter (herein labelled 'M-ESP') database. We also discuss how such information complements more traditional databases of volcanoes and volcanic activity.

\section{Volcanic Ash Advisories}

The International Airways Volcano Watch and VAACs were developed progressively through the 1990s, with the issuance of VAAs beginning in the early 1990s, to inform civil aviation of any observed ash in the atmosphere. VAAs (Fig. 1) are issued by one of nine VAACs (Lechner et al. 2017) which monitor the world's airspace within their respective regions or Areas of Responsibility (AoR; Fig. 2). The purpose of these regional VAACs is to provide guidance to state MWOs. MWOs are responsible for issuing formal information on meteorological phenomena, including the presence of volcanic ash clouds, to aviation. Official warning guidance is provided by a SIGMET (i.e. Significant Meteorological Information) report which gives information to air traffic control offices and airlines on activity or conditions that may affect an aircraft. The SIGMET describes both the event and projected conditions for $6 \mathrm{~h}$ after issuance of the report (Lechner et al. 2009, accessed January 2020). The VAACs have expertise in volcanic-ash-transport-and-dispersion modelling, and analysis of satellite imagery, and work to provide a consistent product as an ash cloud traverses over large regions, often through the AoR of many VAACs and MWOs. The VAACs use information from a number of sources, including SVOs, pilot reports, satellite sensors, and automated tools such as the
VOLCAT (Pavolonis et al. 2018) and the SACS system (Brenot et al. 2014) to identify and monitor ongoing eruptive episodes. When an eruptive and/or ash dispersion event is in progress, the responsible VAAC will initiate volcanic-ashtransport-and-dispersion models using input from Numerical Weather Prediction (NWP) models to simulate the dispersion of volcanic ash and provide forecasts of ash dispersal for 6, 12, and $18 \mathrm{~h}$ into the future, following a structured format. A VAA is issued as soon as the VAAC is notified of an event with the potential to produce ash clouds, or a change in eruptive activity, and VAAs are updated at least every $6 \mathrm{~h}$, or sooner if needed, as long as ash remains in the atmosphere. The International Airways Volcano Watch has 24/7 coverage, and VAAC operations and products adhere to International Civil Aviation Organization (ICAO) requirements using all observations made available to them, including weather satellite data which now has global coverage.

VAAs are issued as text bulletins and are usually accompanied by a Volcanic Ash Graphic (VAG) displaying one or more polygons that represent the observed and forecast location(s) of an ash cloud. Example VAG and VAA are shown in Fig. 1a and b, respectively, and were issued by the Darwin VAAC in response to the 2014 eruptive event at Kelut volcano, Indonesia. The text bulletin reports the time and location of the eruptive event, sources of observations (e.g. ground reports, pilot reports, or satellite imagery), and the observed and forecast distribution of ash in the atmosphere. When possible, VAACs also provide information regarding the volcano aviation colour code, as provided by the responsible SVO. Cloud heights given in VAAs are based on real-time information, as provided by the SVO, and operational analysis of observational data such as satellite or webcam imagery. Although there have been subtle evolutions in the way in which information is reported within the VAAs, the general format is prescribed by the ICAO (ICAO Handbook on the International Airways Volcano Watch: Operational Procedures and Contact List, Doc 9766-AN/968, accessed January 2020) and has not changed significantly through the period used for this study. For some eruptions, additional information, such as lidar or radar, may be available in postanalysis by the VAACs, or in research case studies. This study uses information published in near-real-time only, representing the vast bulk of volcanic cloud analyses available from the VAACs.

\section{Data analysis}

This study analyses VAAs issued related to the emission of volcanic ash at volcanoes in the period from 1 January 2009 to 1 January 2019. Any VAAs issued in the context of VAAC tests or exercises were not included in the analysis. In addition, VAAs referring to information in advisories from other 


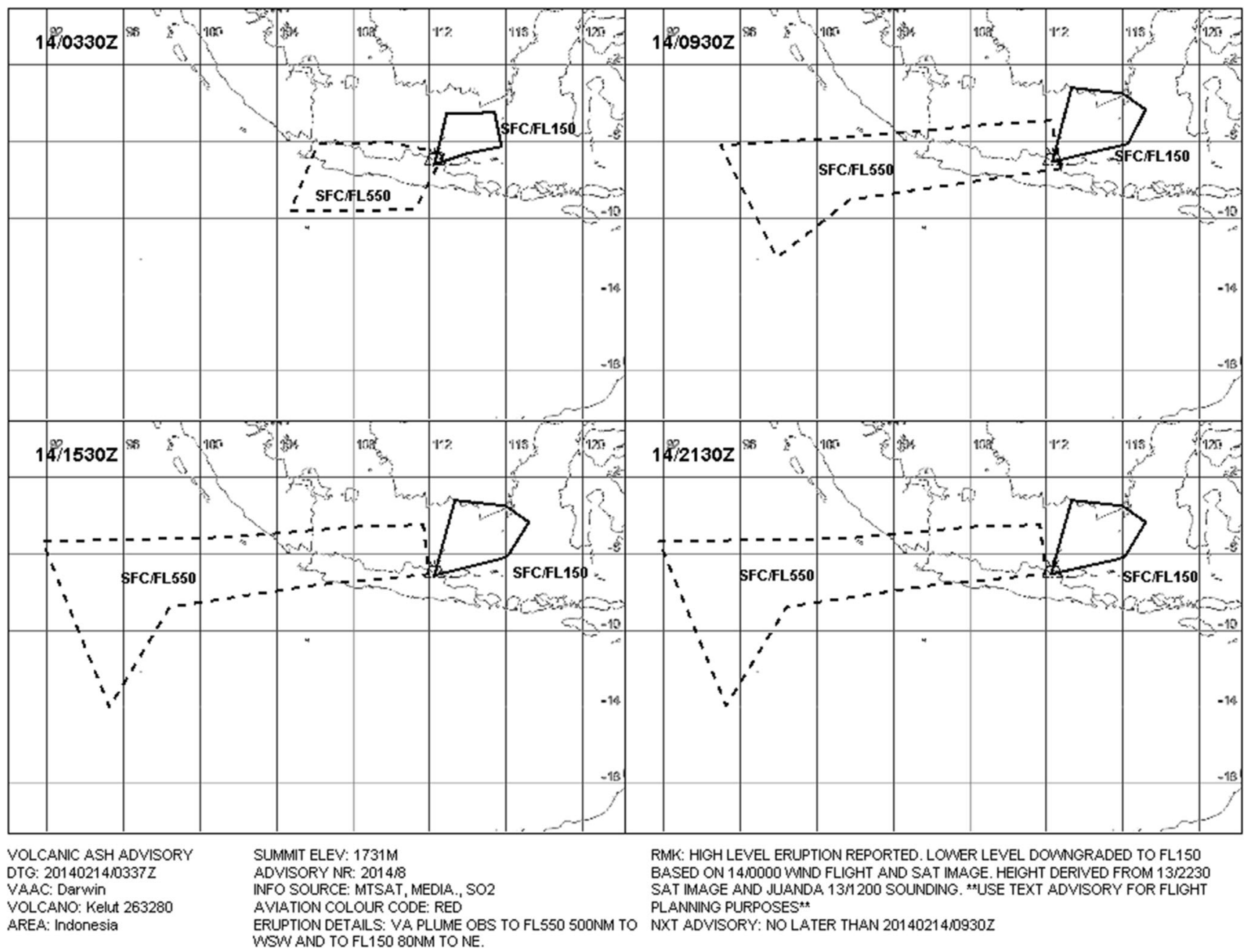

Fig. 1 a An example of a Volcanic Ash Graphic (VAG) issued by Darwin VAAC during the Kelut eruption of 2014 and $\mathbf{b}$ the associated Volcanic Ash Advisory (VAA). Real-time analysis suggested that the resultant plume reached a flight level (FL) of $550(\sim 16.7 \mathrm{~km})$ while post-analysis indicated the eruption was significantly higher. Images courtesy of VAAC Darwin, Bureau of Meteorology Australia, http:// www.bom.gov.au/aviation/volcanic-ash/
VAACs, and all VAAs related to ash resuspension were removed to focus primarily on explosive volcanic events and to avoid duplication of information. Table 1 displays the total number of VAAs issued by each VAAC and by all VAACs for volcanoes in a VAAC region. For almost all VAACs, except London, the total number of advisories issued (column 2 ) is larger than the number issued for volcanoes within their region (column 3). This reflects eruptions with long-range ash dispersal, which affected airspace across multiple VAAC regions. For example, the Darwin, Toulouse, and Wellington VAACs issued VAAs following the 2011 eruption of the Cordon Caulle volcano, which is located within the Buenos Aires VAAC AoR. For the purpose of this analysis, we use the data from the responsible VAAC as they are most likely to contain information on conditions and observations in the atmosphere proximal to the erupting volcano. From each VAA, we extracted the volcano name and location, the advisory date/time, the advisory date/time information for subsequent VAAs, the aviation colour code, the information source, the observed volcanic ash cloud height, the modelled volcanic ash cloud height and extent, and remarks about the volcanic activity.

While some eruptive information can be directly extracted from the VAAs, for example plume height, other information, specifically definition of an eruptive event, is inferred from the contained data. Rather than using the definition of an event in the general volcanic sense (Siebert et al. 2015; Jenkins et al. 2007), here we define an event as a volcanic incident that prompts the issuance of a group of VAAs. Groups were defined using the 'Next Advisory' field in the VAAs (Fig. 1b), which typically state when a period of ash emission is over and volcanic ash is no longer observed in the atmosphere. Event duration was calculated 
IDD41295

VA ADVISORY

DTG: $20140214 / 03372$

VAAC: Darwin

VOLCANO: Kelutt 263280

PSN: S0756 E11219

AREA: Indonesia

SUMMIT ELEV: $1731 \mathrm{M}$

ADVISORY NR: $2014 / 8$

INFO SOURCE: MTSAT, MEDIA., S02

AVIATION COLOUR CODE: RED

ERUPTION DETAILS: VA PLUME OBS TO FL550 500NM TO WSW AND TO FL150

80NM TO NE.

OBS VA DTG: $14 / 0330 Z$

OBS VA CLD:

SFC/FL150 S0755 E11215 - S0515 E11255 - S0510 E11525 S0700 E11545 - S0720 E11400 - S0755 E11215 MOV NE 15KT SFC/FL550 S0720 E11245 - S1015 E11115 - S1020 E10445 S0650 E10610 - S0645 E11000 - S0720 E11245 MOV SW 60KT

FCST VA CLD +6HR: $14 / 0930 Z$

SFC/FL150 S0745 E11220 - S0350 E11320 - S0410 E11600 S0500 E11710 - S0650 E11615 - S0745 E11220

SFC/FL550 S0805 E11245 - S0945 E10145 - S1245 E09755 -

S0655 E09500 - S0625 E10245 - S0550 E10845 - S0535 E11215 -

S0805 E11245

FCST VA CLD +12HR: $14 / 1530 Z$

SFC/FL150 S0750 E11215 - S0350 E11320 - S0410 E11600 -

S0500 E11710 - S0645 E11610 - S0700 E11540 - S0750 E11215

SFC/FL550 S0510 E11140 - S0745 E11200 - S0820 E10600 -

S0930 E09825 - S1440 E09515 - S0600 E09145 - S0550 E10130 -

S0515 E10830 - S0510 E11140

FCST VA CLD +18HR: $14 / 2130 \mathrm{Z}$

SFC/FL150 S0745 E11215 - S0350 E11320 - S0410 E11600 -

S0500 E11710 - S0650 E11610 - S0700 E11545 - S0745 E11215

SFC/FL550 S0600 E09145 - S0555 E10130 - S0515 E10825 -

S0510 E11140 - S0745 E11200 - S0820 E10600 - S0930 E09825 -

S1435 E09515 - S0600 E09145

RMK: HIGH LEVEL ERUPTION REPORTED. LOWER LEVEL DOWNGRADED TO

FL150 BASED ON $14 / 0000$ WIND FLIGHT AND SAT IMAGE. HEIGHT DERIVED

FROM $13 / 2230$ SAT IMAGE AND JUANDA $13 / 1200$ SOUNDING. **USE TEXT

ADVISORY FOR FLIGHT PLANNING PURPOSES**

NXT ADVISORY: NO LATER THAN 20140214/0930Z

Copyright Commonwealth of Australia 2011, Bureau of Meteorology (ABN 92637533

532). Users of these web pages are deemed to have read and accepted the

conditions described in the Copyright, Disclaimer, and Privacy statements

(http://ww. bom.gov.au/other/copyright.shtml).

Fig. 1 (continued)

as the time difference between the first and last VAAs of the group. Notably, the 'events' reported here do not describe the duration of the volcanic activity or emissions, but the time over which volcanic ash is observed in the atmosphere.
Although we use event duration as a proxy for the duration of ash emission from the ground, depending on the residence time of ash in the atmosphere, the actual duration of ash emission is likely to be shorter. 
Fig. 2 Map of the VAAC areas of responsibility and active volcanoes in the period between 1 January 2009 and 1 January 2019. Symbol colour represents the $\log 10$ number of VAAs. Black symbols represent those volcanoes that have been active within the Holocene period (GVP Smithsonian Institute)

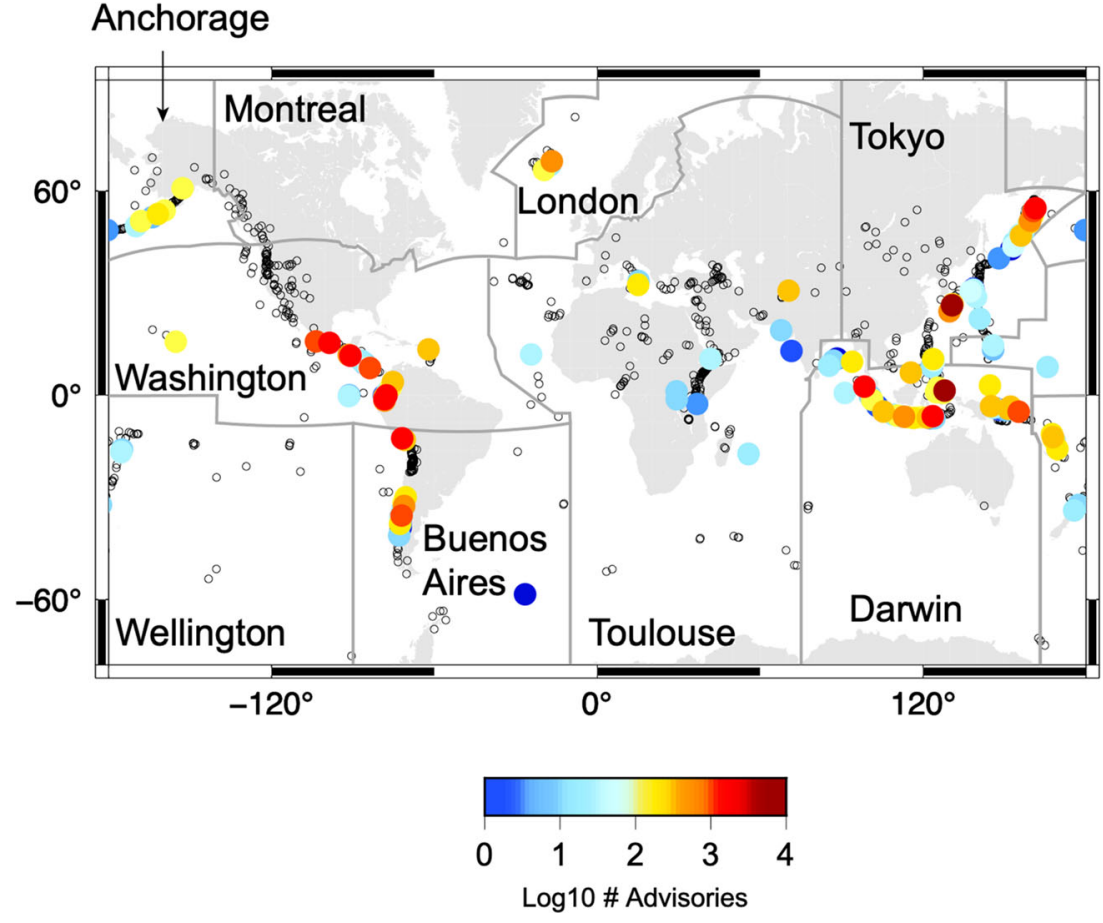

Volcanic ash cloud heights reflect the intensity of an explosive event (Sparks et al. 1997). Because VAAs are directed primarily to the aviation sector, volcanic cloud height is reported as flight level and describes the top of the laterally spreading volcanic cloud. Flight level (FL) is the altitude of an aircraft at the standard air pressure, expressed in hundreds of feet $(1 \mathrm{FL}=100 \mathrm{ft})$, and herein is used as a proxy for altitude. For our analysis, we use the observed flight level of the ash cloud in preference to the modelled flight level (shown under 'FCST VA CLD'). The observed flight level is directly informed by real-time observations by the SVO or through analysis of satellite imagery or other observations. However,

Table 1 Number of VAAs issues in the period between 1 Jan 2009 and 1 Jan 2019. Column 2 shows the total number of VAAs issued by each VAAC in this period, excluding test advisories. Column 3 shows the number of advisories issued for volcanoes in a given VAAC region (e.g. VAAs issued by the Anchorage VAAC for volcanoes within the Anchorage VAAC region)

\begin{tabular}{lll}
\hline VAAC & No. of VAA issued & $\begin{array}{l}\text { No. of VAA issued for volcanoes } \\
\text { VAAC region }\end{array}$ \\
\hline Anchorage & 966 & 621 \\
Buenos Aires & 5876 & 5589 \\
Darwin & 18,153 & 18,060 \\
London & 178 & 178 \\
Toulouse & 505 & 438 \\
Tokyo & 15,861 & 15,422 \\
Washington & 15,456 & 15,374 \\
Wellington & 1268 & 1129 \\
Montreal & 36 & 0 \\
\hline
\end{tabular}

there are some examples where direct observations of an ash cloud are not available, for example due to obscuration by meteorological clouds. In such cases, observed flight level information is not provided, and the modelled flight level is estimated based on previous knowledge of activity at a volcano and NWP data. Therefore, the modelled flight level includes examples where there are no direct observations of flight level, while the observed flight level is a more consistently informed estimate of explosive activity at a volcano and is more certain. The observed flight level is often recorded at multiple locations within the VAAs, typically within the 'ERUPTION DETAILS', 'EST', or 'OBS cloud' fields (Fig. 1b), and occasionally within the 'REMARKS' or 'RMK' section. In cases when two flight levels were given describing ash transport at multiple altitudes, we chose the greater one, yielding results that represent an upper measure of the observed volcanic ash cloud height.

The key to analysis of data within the VAAs is the comparison with information more commonly used to characterise volcanic activity. Here, we used the M-ESP database to aid interpretation. The M-ESP database was developed primarily to aid implementation of numerical simulation of ash dispersion in the atmosphere. The database, co-authored by representatives from all nine VAACs, represents a multidisciplinary effort to assign ESPs to volcanoes. Mastin et al. (2009a) identify eleven eruption categories, characterised by a specific magma type and eruption size (Table 2). These categories describe eruption scenarios of different scales. Each eruption category was assigned a characteristic volcanic 
Table 2 Eruption types and plume height and duration in the Mastin et al. (2009a) eruption source parameter (M-ESP) database. H and D show the cloud height and duration, respectively, as assigned to each category in the database

\begin{tabular}{|c|c|c|c|c|}
\hline Type & Magma type & Historical eruption characteristics & $\mathrm{H}$ (km above the vent) & $\mathrm{D}(\mathrm{h})$ \\
\hline Mafic, standard (M0) & \multirow[t]{4}{*}{ Basalt or other mafic } & Insufficient historical data to characterise & 7 & 60 \\
\hline Small (M1) & & $\mathrm{H} \leq 5 \mathrm{~km}$ or $\mathrm{VEI} \leq 2$ & 2 & 100 \\
\hline Medium (M2) & & $\mathrm{H}=5-8 \mathrm{~km}$ or $\mathrm{VEI}=3$ & 7 & 60 \\
\hline Large (M3) & & $>8 \mathrm{~km}$ or $\mathrm{VEI} \geq 4$ & 10 & 5 \\
\hline Silicic, standard (S0) & \multirow{6}{*}{$\begin{array}{l}\text { Andesite, dacite, rhyolite, or other } \\
\text { explosive composition }\end{array}$} & Insufficient historical data to characterise & 11 & 3 \\
\hline Small (S1) & & $\mathrm{H} \leq 6 \mathrm{~km}$ or $\mathrm{VEI} \leq 2$ & 5 & 12 \\
\hline Medium (S2) & & $\mathrm{H}=6-12 \mathrm{~km}$ or $\mathrm{VEI}=3$ & 11 & 3 \\
\hline Large (S3) & & $\mathrm{H} \geq 12 \mathrm{~km}$ or $\mathrm{VEI} \geq 4$ & 15 & 8 \\
\hline Co-ignimbrite cloud (S8) & & $\begin{array}{l}\text { Major pyroclastic flows, with an elutriated column } \\
\text { rising primarily above the flows }\end{array}$ & 25 & 0.5 \\
\hline Brief (S9) & & Active lava dome is present & 10 & 0.01 \\
\hline Submarine (U0) & All magma types & Submarine vent with a water depth $\geq 50 \mathrm{~m}$ & 0 & - \\
\hline
\end{tabular}

cloud height, duration, erupted volume, and mass fraction of fine ash. An eruption type of 'medium silicic (S2)' for example, based on the 1992 Mount Spurr (Alaska) eruption (Neal et al. 1995), was assigned a volcanic cloud height of $11 \mathrm{~km}$ above vent and a duration of $3 \mathrm{~h}$. A sister publication (Mastin et al. 2009b) includes a spreadsheet that assigned these eleven eruption types to each of the 1500 volcanoes active in the Holocene in the Volcanoes of the World database maintained by the Smithsonian Institution Global Volcanism Program (GVP). The assignments were based on observed patterns of eruptive behaviour at each volcano or, for volcanoes that had not erupted in historical time, on the type of volcano or magma type, using information from the GVP database and published records. The categories M0 (mafic standard) and S0 (silicic standard) are default values assigned to volcanoes that lack sufficient historical information to merit more defined categories. In these cases, parameters are assigned using the medium-sized eruption categories M2 (mafic medium) and S2 (silicic medium), respectively.

\section{Results}

\section{Volcano advisories through time}

From 1 January 2009 to 1 January 2019, more than 57,500 VAAs were issued describing activity at 139 volcanoes (Table 3; Fig. 2). A majority of these VAAs were issued by the Darwin, Tokyo, Buenos Aires, and Washington VAACs, detailing explosive volcanic activity across Indonesia, Japan, the Kamchatka Pensinsula, and Central America and South America. Fifty percent of the VAAs were related to activity at just eight volcanoes (Sakurajima 12\%, Dukono 11.5\%,
Reventador $4.75 \%$, Sabancaya $4.5 \%$, Sheveluch $4.3 \%$, Tungurahua $4.2 \%$, Batu Tara 3.9\%, Sinabung 3.9\%).

There is a direct correlation between the number of VAAs and the number of events per volcano, with Sakurajima having the greatest number of calculated events $(32 \%$ of the total number of events). Again, 50\% of these events are from a small number of volcanoes (Sakurajima 32\%, Sheveluch $5.2 \%$, Asosan 5\%, Sinabung 4.4\%, and Suwanosejima 4\%).

Cumulative plots of the number of VAAs per month (Fig. 3) show that although the number of VAAs issued by many VAACs is relatively constant through time, with an almost constant slope in the cumulative number of issued VAAs, there are periods with a marked increase in the issued number of VAAs. For VAACs such as London that responded to few events, peaks associated with individual eruptions (e.g. Eyjafjallajökull in 2010 and Grímsvötn in 2011) are clear. For those that issue many VAAs (e.g. Darwin, Washington, and Tokyo), it is difficult to identify increases in the number of VAAs associated with volcanic activity at individual volcanoes. There is, however, a change in slope in cumulative VAAs from 2015 to 2019. This trend is seen when all VAAs are analysed (Fig. 3), but it is also evident for those VAACs that issue numerous VAAs, particularly Washington and Buenos Aires. The number of explosive eruptive events per VAAC (Fig. 3) is considerably lower than the number of advisories issued, indicating that a majority of events are described by multiple VAAs. Despite the large difference in number, for the most part, trends in the number of explosive events per VAAC closely match those of total VAAs issued.

An increase in the frequency of VAA issuance could result from increased explosive volcanic activity, increased observational information to trigger advisories (including from ground and satellite-based observations), or procedural changes within the VAACs. To understand whether this increase reflects an upward trend in volcanic activity, the VAA data 
Table 3 Number of VAAs and calculated events for volcanoes within each VAAC area of responsibility between 1 January 2009 and 1 January 2019. See text for definition of 'event'

\begin{tabular}{|c|c|c|c|c|c|}
\hline Volcano & VAAs (events) & Volcano & VAAs (events) & Volcano & VAAs (events) \\
\hline Anchorage & & Darwin cont. & & Toulouse & \\
\hline Bogoslof & $132(49)$ & Paluweh & $371(33)$ & Etna & $280(145)$ \\
\hline Cleveland & $33(16)$ & Rabaul & $454(52)$ & Fogo & $52(3)$ \\
\hline Pavlof & $192(13)$ & Raung & $230(20)$ & Meru & $4(2)$ \\
\hline Redoubt & $136(15)$ & Rinjani & $268(29)$ & Nabro & $42(10)$ \\
\hline Semisopochnoi & $4(1)$ & Sakar & $2(1)$ & Nyamuragira & $15(8)$ \\
\hline Shishaldin & $9(4)$ & Sangeang Api & $111(20)$ & Nyiragongo & $15(7)$ \\
\hline Veniaminof & $115(20)$ & Semeru & $87(26)$ & Piton de la Fournaise & $19(18)$ \\
\hline Buenos Aires & & Sinabung & $2218(802)$ & Stromboli & $11(11)$ \\
\hline Antuco & $2(2)$ & Sirung & $11(4)$ & Washington & \\
\hline Bristol Island & 1 & Slamet & $26(12)$ & Colima & 1487 (419) \\
\hline Calbuco & $70(13)$ & Soputan & $135(18)$ & Concepcion & $5(2)$ \\
\hline Callaqui & $9(7)$ & Tengger Caldera & $714(41)$ & Cotopaxi & $333(60)$ \\
\hline Cerro Hudson & $10(1)$ & Ulawun & 337 (39) & Fernandina & $42(7)$ \\
\hline Chaiten & $218(153)$ & London & & Fuego & $1874(480)$ \\
\hline Copahue & $617(150)$ & Eyjafjallajokull & $150(58)$ & Galeras & $40(10)$ \\
\hline Cordon Caulle & $1557(93)$ & Grimsvotn & $28(23)$ & Guagua Pichincha & $2(1)$ \\
\hline Lascar & $11(9)$ & Bardabunga & $7(1)$ & Huila & $167(31)$ \\
\hline Llaima & $10(9)$ & Tokyo & & Kilauea & $153(33)$ \\
\hline Nevado Chachani & $3(1)$ & Alaid & $51(18)$ & Masaya & $16(7)$ \\
\hline Nevados de Chillan & $147(99)$ & Asamayama & $39(38)$ & Momotombo & $44(15)$ \\
\hline Osorno & $1(1)$ & Asosan & $938(914)$ & Negra, Sierra & $51(9)$ \\
\hline Palena Volcanic Group & $1(1)$ & Bezymianny & $103(26)$ & Pacaya & $81(21)$ \\
\hline Planchon Peteroa & $182(44)$ & Bulusan & $79(68)$ & Pagan & $41(17)$ \\
\hline Sabancaya & $2568(191)$ & Chikurachki & $45(9)$ & Poas & $78(28)$ \\
\hline Ubinas & 417 (147) & Chirinkotan & $27(8)$ & Popocatepetl & $2152(610)$ \\
\hline Villarrica & $52(30)$ & Ebeko & $474(265)$ & Reventador & $2733(714)$ \\
\hline Darwin & & Etorofu-Yakeyama & $4(4)$ & Rincon de la Vieja & $20(9)$ \\
\hline Agung & $426(85)$ & Kambalny & $22(7)$ & Ruiz & $476(159)$ \\
\hline Bagana & $1351(175)$ & Kanlaon & $27(19)$ & San Cristobal & $10(2)$ \\
\hline Barren Island & $206(32)$ & Karymsky & $724(305)$ & San Miguel & $1(1)$ \\
\hline Batu Tara & $2248(126)$ & Ketoi & $1(1)$ & Sangay & $605(162)$ \\
\hline Dempo & $3(1)$ & Kirishima & $329(197)$ & Santa Maria & $778(325)$ \\
\hline Dukono & $6644(334)$ & Kizimen & $239(79)$ & Sarigan & $7(1)$ \\
\hline Gamalama & $105(14)$ & Klyuchevskoy & $1394(387)$ & Soufriere_Hills & $510(17)$ \\
\hline $\mathrm{Ibu}$ & $91(66)$ & Koryaksky & $74(30)$ & Telica & $30(12)$ \\
\hline Kadovar & $189(16)$ & Kuchinoerabujima & $239(225)$ & Tungurahua & $2422(273)$ \\
\hline Karangetang & $105(23)$ & Kusatsu-Shiranesan & $1(1)$ & Turrialba & $1207(243)$ \\
\hline Karkar & $36(6)$ & Mayon & $206(145)$ & Volcan Wolf & $9(2)$ \\
\hline Kelut & $22(1)$ & Miyakejima & $5(5)$ & Wellington & \\
\hline Kerinci & $132(29)$ & Nishinoshima & $31(18)$ & Ambae & $358(51)$ \\
\hline Krakatau & $417(72)$ & Ontakesan & $70(59)$ & Ambrym & $134(23)$ \\
\hline Langila & $341(73)$ & Sakurajima & $6931(5900)$ & Gaua & $297(4)$ \\
\hline Lewotobi & $5(1)$ & Sarychev-Peak & $91(13)$ & Lopevi & $9(3)$ \\
\hline Lokon-Empung & $87(36)$ & Satsuma-Iojima & $2(2)$ & Tinakula & $25(1)$ \\
\hline Manam & $501(94)$ & Sheveluch & $2490(1000)$ & Tofua & $10(2)$ \\
\hline Marapi & $11(7)$ & Suwanosejima & $875(741)$ & Hunga Tonga-Hunga Ha'apai & $46(6)$ \\
\hline Merapi & $170(19)$ & Tolbachik & $16(12)$ & Tongariro/Ngauruhoe & $20(5)$ \\
\hline \multirow[t]{2}{*}{ Pago } & $6(2)$ & Zhupanovsky & $334(144)$ & White Island & $12(3)$ \\
\hline & & & & Yasur & $218(31)$ \\
\hline
\end{tabular}

are compared with explosive eruption data for the same time period from the GVP database (https://volcano.si.edu/; data accessed 29 January 2019). To make the datasets comparable, GVP entries described as non-explosive or events such as the evacuation of local communities were removed. With this adjustment, curves showing the cumulative number of explosive events (Fig. 4) show a fairly constant slope with time, in contrast to the time-increasing slope of the number of VAAs and eruptive events reported by VAAs
(Fig. 3). The cumulative number of VAAs issued based on satellite imagery (Fig. 3) shows the same inflection representing an increase in the number of VAAs in recent years. We see little discrepancy between total and satellitebased VAAs for London, Washington, Buenos Aires, and Darwin VAACs, whereas Tokyo VAAC shows a distinct increase in satellite-based VAAs from 2015.

To further investigate the source of this increase in the number of issued VAAs, the number of VAAs per flight level is shown, 


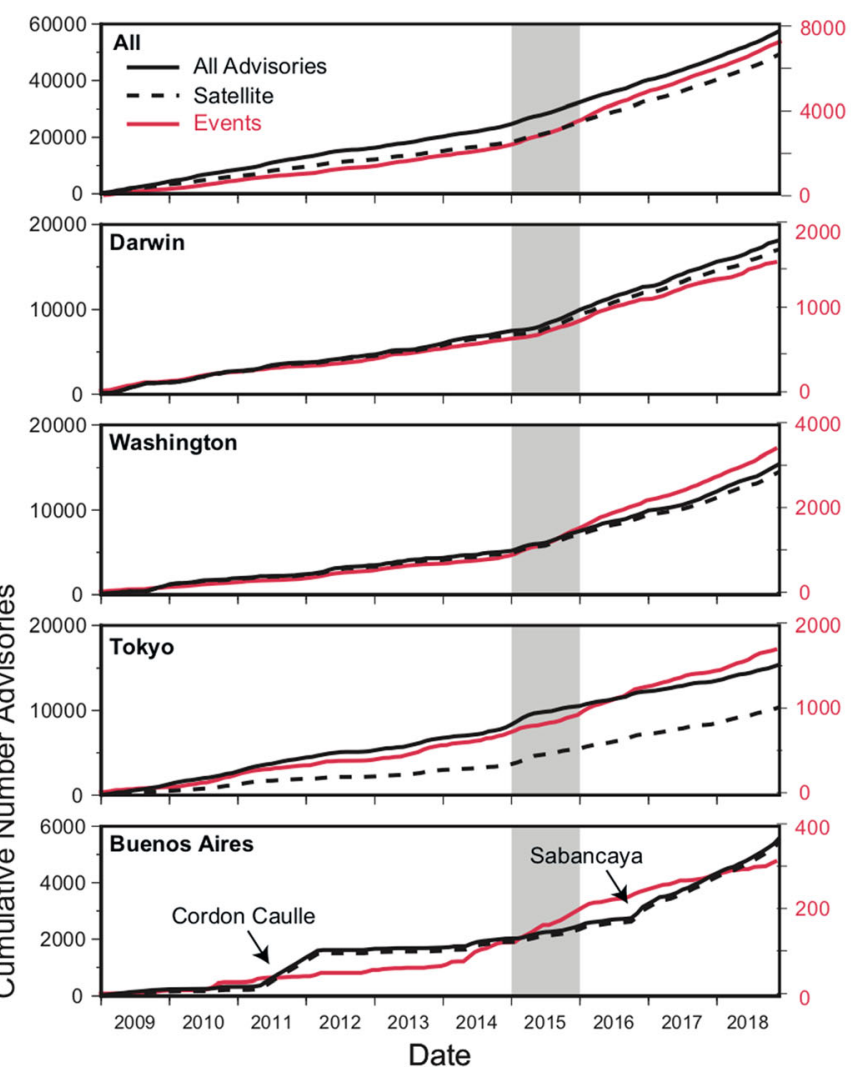

Fig. 3 Cumulative number of VAAs per VAAC (black lines), cumulative number of advisories citing satellite data as an information source (black dashed lines), and number of events according to advisories (red line).

with a 6-month rolling mean to identify trends in the data. VAAs were binned according to their FL (Fig. 5). Bins of 100 were chosen to display FL data, as FL is typically reported in FL10, 50 , or $100(\sim 0.3,1.5,3 \mathrm{~km})$ increments, and to enable comparison of low plumes with larger plumes. Since 2015, there has been a significant increase in the number of VAAs at lower flight levels, particularly FL101-FL200 (3-6 km asl (above sea level)). For FL $<100(<3 \mathrm{~km}$ asl) and FL201-300 (6-9 km asl), the increase in the total number of VAAs with time has been more gradual. Trends are more difficult to identify for VAAs with FL greater than $400(12 \mathrm{~km})$ due to the lower numbers of VAAs; however, the data do not show evidence of this increase with
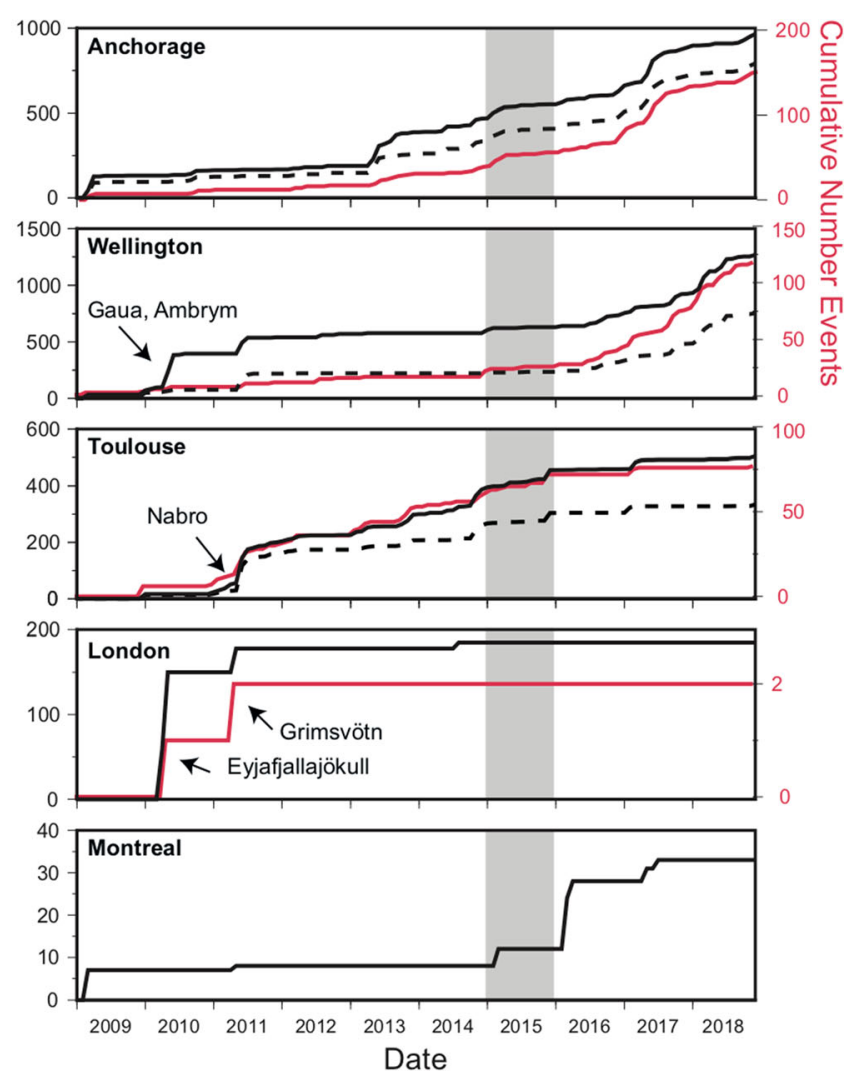

Grey vertical bar highlights the period in which a change in the rate of VAA issuance occurs

time, likely due to the relative ease to identify volcanic clouds that reach stratospheric levels. Given the relative scarcity of eruptions that produce volcanic clouds that reach flight levels of up to FL400, it is possible to attribute peaks in the number of advisories to specific eruptions (Fig. 5).

\section{Volcano classification}

Each of the volcanoes with VAAs within the 2009-2019 period was grouped according to the categories within the M-ESP database. This enables an assessment of the appropriateness of these categories for ash and aviation purposes. Most VAAs
Fig. 4 Cumulative number of events for each VAAC through the analysis of the Smithsonian GVP record of events (downloaded on 29 Jan 2019)

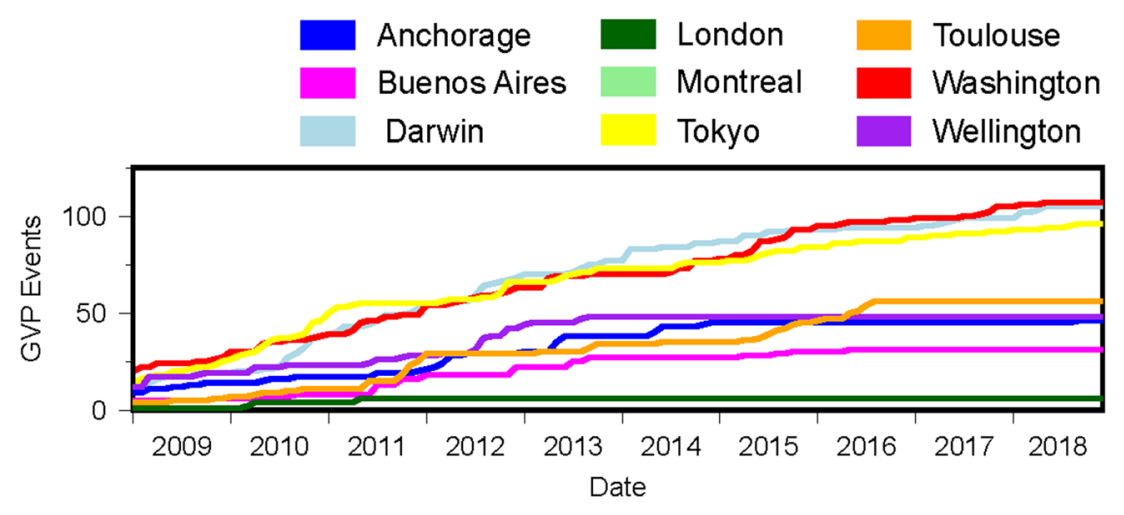



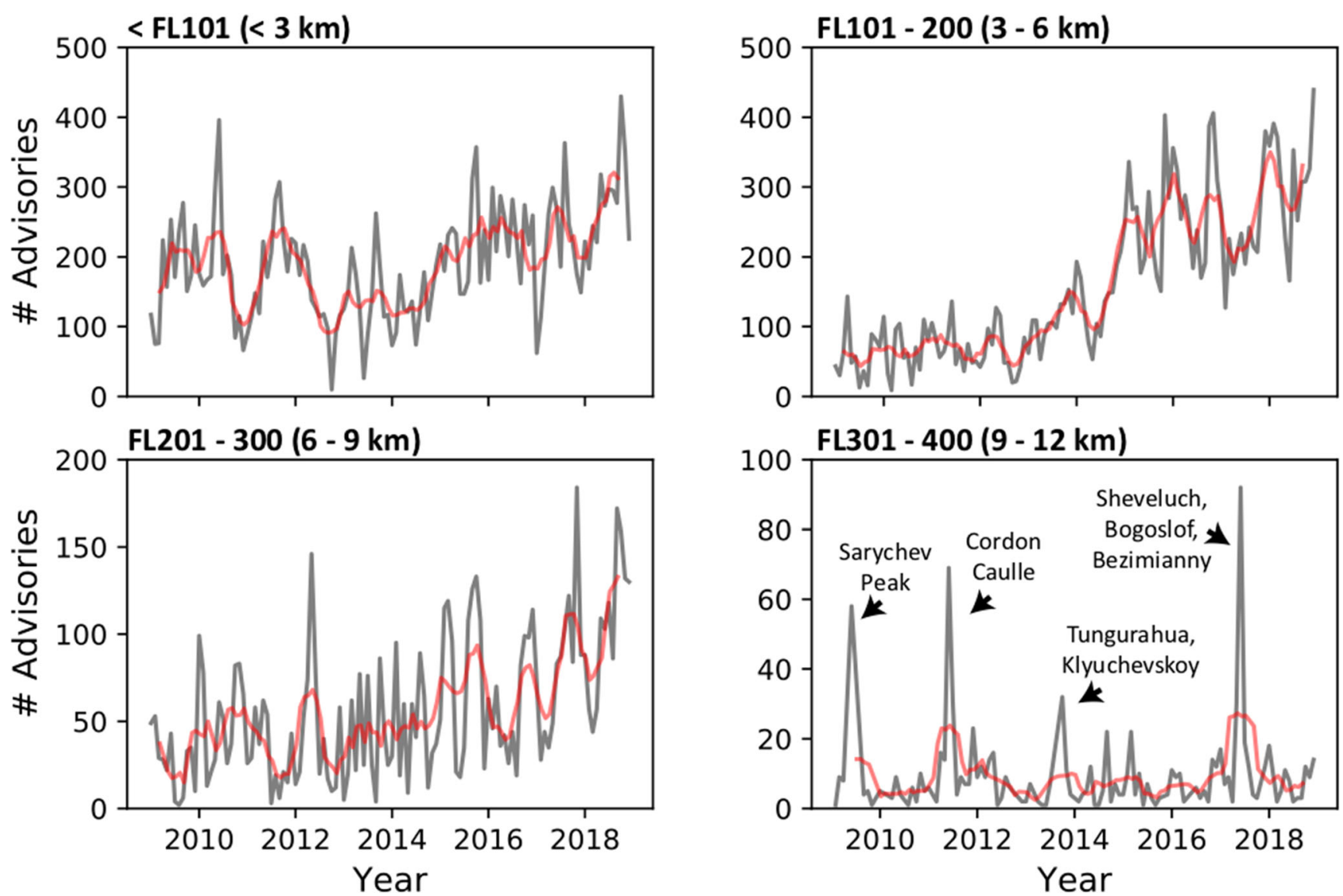

Fig. 5 Number of VAAs per month for FL0-FL100, FL101-FL200, FL201-FL300, and FL301-FL400. The grey line shows the number of VAAs; the red line shows the 6-month average number of VAAs

issued between 2009 and 2019 were related to volcanoes characterised as silicic small type (S1 Mastin et al. 2009b, Table 2, Fig. 6), although there were also many mafic small (M1), silicic standard (S0), and silicic medium (S2) types. There were comparatively few eruptions at mafic standard (M0), mafic medium (M2), silicic large (S3), or 'brief' (S9) type volcanoes. There were no VAAs for volcanoes classified as mafic large (M3) or submarine (U0). These classifications reflect

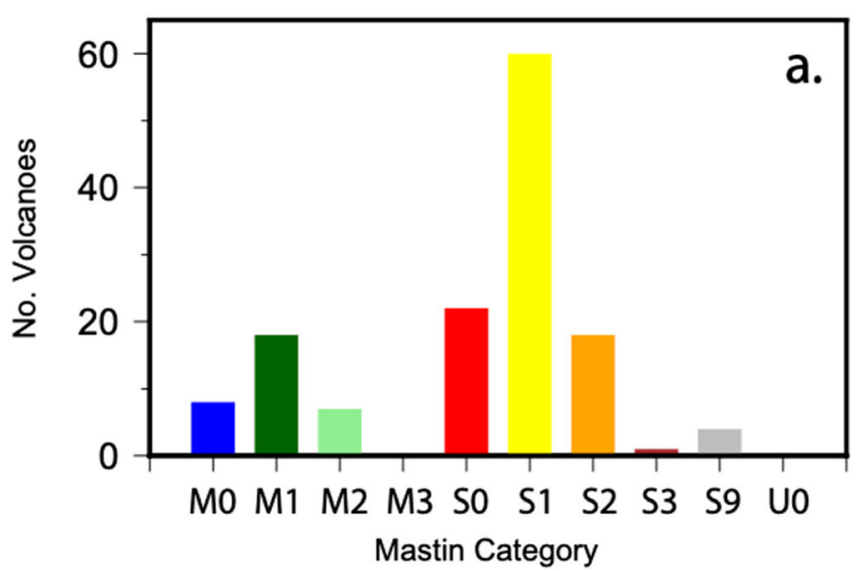

expectations of volcanic activity, whereby smaller eruptions (i.e. silicic small or mafic small) occur more frequently than larger events. Volcanoes classified as M0 and S0 make up a large proportion of the entries in the M-ESP database (32\% M0, $44.2 \%$ S0; Fig. 6b). However, only a relatively small proportion of the volcanoes that have erupted in the past 10 years are assigned to these categories (5\% M0, 17\% S0; Fig. 6). This implies that over a selected short time period (e.g. 10 years),

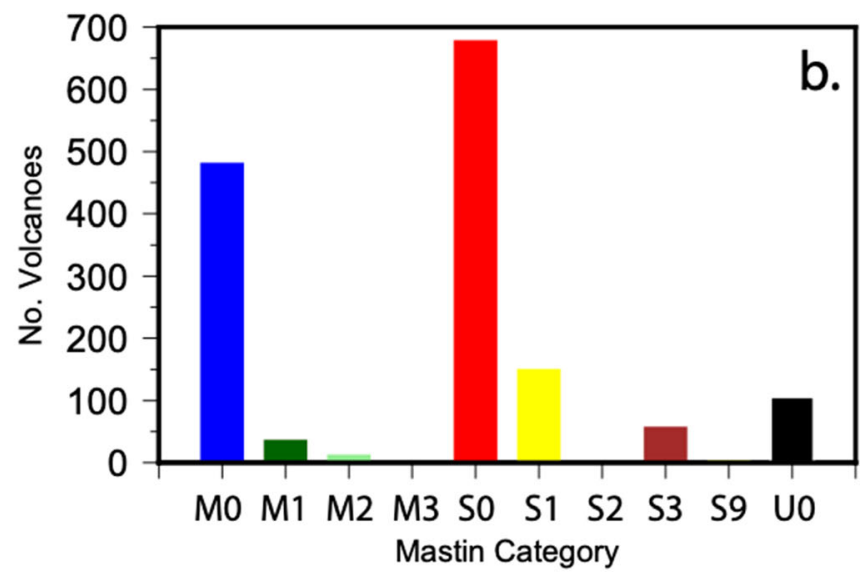

Fig. 6 a Number of volcanoes with VAAs between 1 Jan 2009 and 1 Jan 2019 at volcanoes assigned to each eruption source parameter in Mastin et al. (2009a) (M-ESP) database category (see Table 2). b Number of volcanoes per category within the M-ESP database 

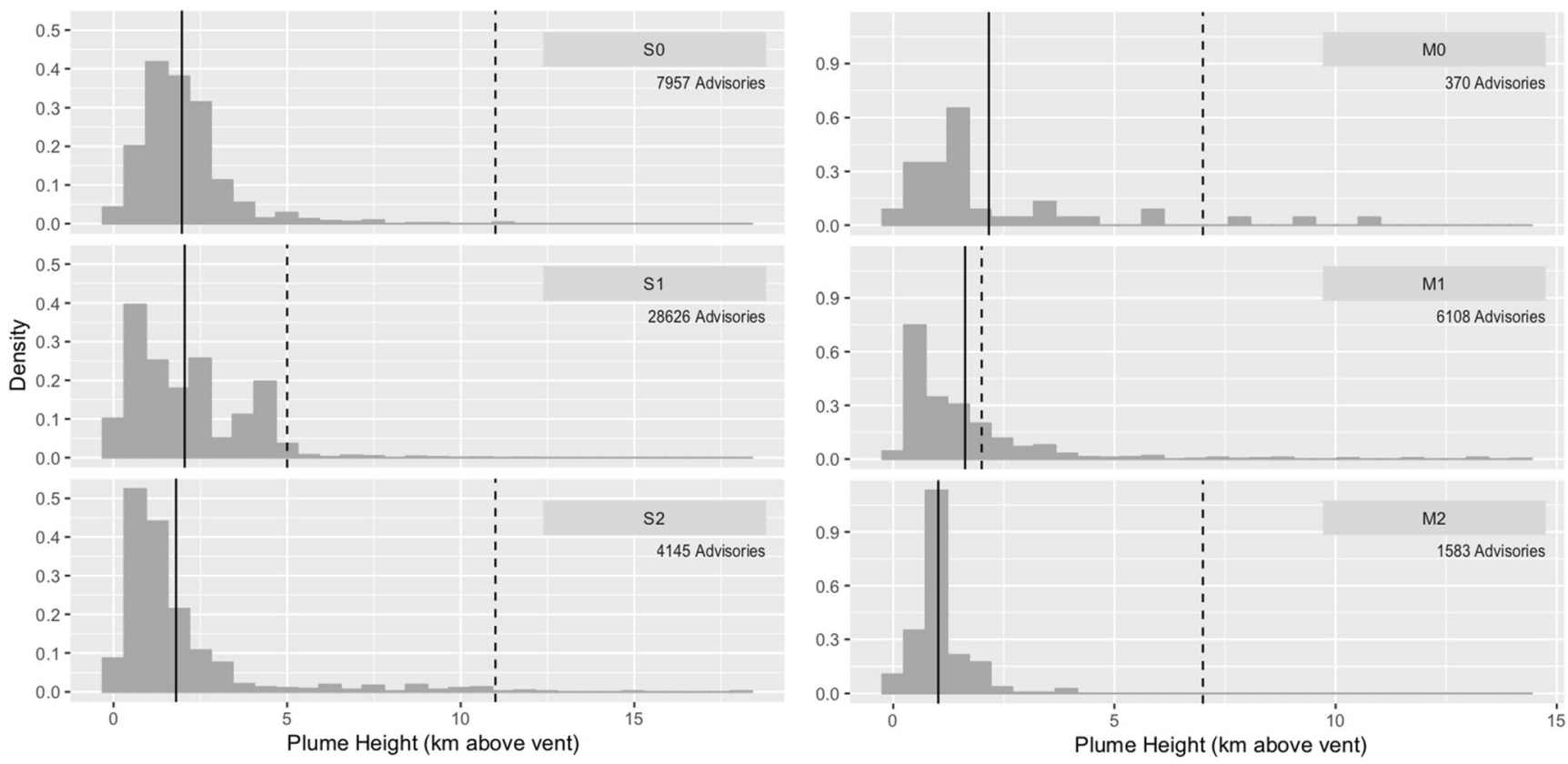

Fig. 7 Density plot of plume height ( $\mathrm{km}$ above the vent converted from FL) reported in VAAs per M-ESP category. The solid line shows the average plume height from the VAAs, while the dashed line shows the height allocated per M-ESP category

volcanoes that have erupted recently, frequently, or are in longterm eruption are most likely to show explosive activity.

To understand how the activity reported within the VAAs relates to expected activity for a given volcano, we analyse the average volcanic ash cloud height per event in relation to that assigned by the M-ESP database. The M-ESP database was produced to provide inputs to volcanic-ash-transport-and-dispersion models. Cloud height within the M-ESP database refers to 'the elevation at which most ash spreads laterally from the plume into the volcanic cloud' (Mastin et al. 2009a). However, Mastin et al. (2009a) noted that the observations of maximum plume height are more frequently available than the heights of the dispersing volcanic cloud and that maximum plume height has been used to inform M-ESP categories out of necessity.

Figure 7 shows density distribution plots of observed volcanic ash cloud height ( $\mathrm{km}$ above vent; converted from FL). For comparison with the M-ESP volcanic ash cloud heights,

Table 4 Comparison of VAA-derived average plume height versus M-ESP database plume height for each category. All plume heights above the vent

Mastin et al. VAA mean plume Mastin et al. (2009a, Difference $(2009 \mathrm{a}, \mathrm{b}) \quad$ height with one SD $\quad$ b) plume height $(\mathrm{km} \quad(\%)$ category (km above vent) above vent)

\begin{tabular}{llll}
\hline S0 & $1.97 \pm 1.3$ & 11 & +82 \\
S1 & $2.05 \pm 1.6$ & 5 & +59 \\
S2 & $1.80 \pm 2.19$ & 11 & +83 \\
M0 & $2.16 \pm 2.3$ & 7 & +69 \\
M1 & $1.62 \pm 1.78$ & 2 & +19 \\
M2 & $1.01 \pm 0.56$ & 7 & +86 \\
\hline
\end{tabular}

the VAA volcanic ash cloud heights were converted to the height above the vent by subtracting the summit elevation reported in the GVP database for each volcano. The number of events for the S3 and S9 categories was deemed too low for analysis. All of the density plots show skewed distributions with long tails towards greater volcanic ash cloud heights. A majority of the distributions show a single peak, while S1 has a polymodal distribution. For all of the categories, the average volcanic cloud height evaluated from the VAAs is close to $2 \mathrm{~km}$, being slightly lower for the M1 and M2 categories.

The dashed line in Fig. 7 represents the M-ESP-assigned volcanic cloud height (Table 2). For most categories, the VAA average volcanic cloud height is considerably lower than that assigned within the M-ESP database (Fig. 7, Table 4). For the S0, M0, S2, and M2 categories, the M-ESP-assigned volcanic cloud height falls on the upper tail of the distributions, and there is a large difference between the average VAA volcanic cloud height and the M-ESP database height. For the S1 category, the M-ESP volcanic cloud height is $59 \%$ greater than the average height from the advisories $(5 \mathrm{~km}$ vs. $2.05 \mathrm{~km}$; Table 4), but it falls within the distribution. The M-ESP volcanic cloud height for the M1 category is $19 \%$ greater than the average volcanic cloud height from the VAAs (Table 4).

Parameters within the M-ESP database represent the most likely future activity at a volcano given knowledge of previous eruptive behaviour. To understand how these parameters relate to observations reported in VAAs, we compare the average VAA volcanic cloud height and duration per volcano with the M-ESPassigned parameters (Fig. 8). A majority of the volcanoes have similar average plume heights and durations, despite different MESP categories. Most volcanoes have an average VAA volcanic 
cloud height of less than $5 \mathrm{~km}$ and a duration in the region 1$100 \mathrm{~h}$. For the most part, the assigned M-ESP parameters are towards the upper end but within the region of observed volcanic cloud heights as informed by the VAAs (Fig. 8), and this is particularly true for the M1 and S1 categories. The assigned plume heights for the $\mathrm{S} 0$ and $\mathrm{M} 2$ categories are higher than those shown by the VAA data, while for the M0, S1, and S2 volcanoes, the 99th percentile volcanic cloud height approaches the M-ESP volcanic cloud height. This indicates that the M-ESP categories more closely represent the upper plume height limits rather than the average behaviour.

Because duration within the M-ESP database refers to the duration of emission, whereas that calculated herein refers to the duration of observed ash in the atmosphere, we expect the MESP database duration to be shorter than that determined through our analysis of the VAAs. This is seemingly the case for the $\mathrm{S} 0$ and S2 categories and to a lesser extent the S1 category. However, for the M0, M1, and M2 categories, the M-ESP duration falls towards the upper end of that calculated from the VAAs. In comparison, the sparse data for S9 volcanoes show a VAA duration considerably larger than that within the M-ESP database.

Figure 9 shows convex hulls, whereby the smallest convex polygon that encloses the average plume height and duration for all volcanoes within each M-ESP category is drawn. This plot
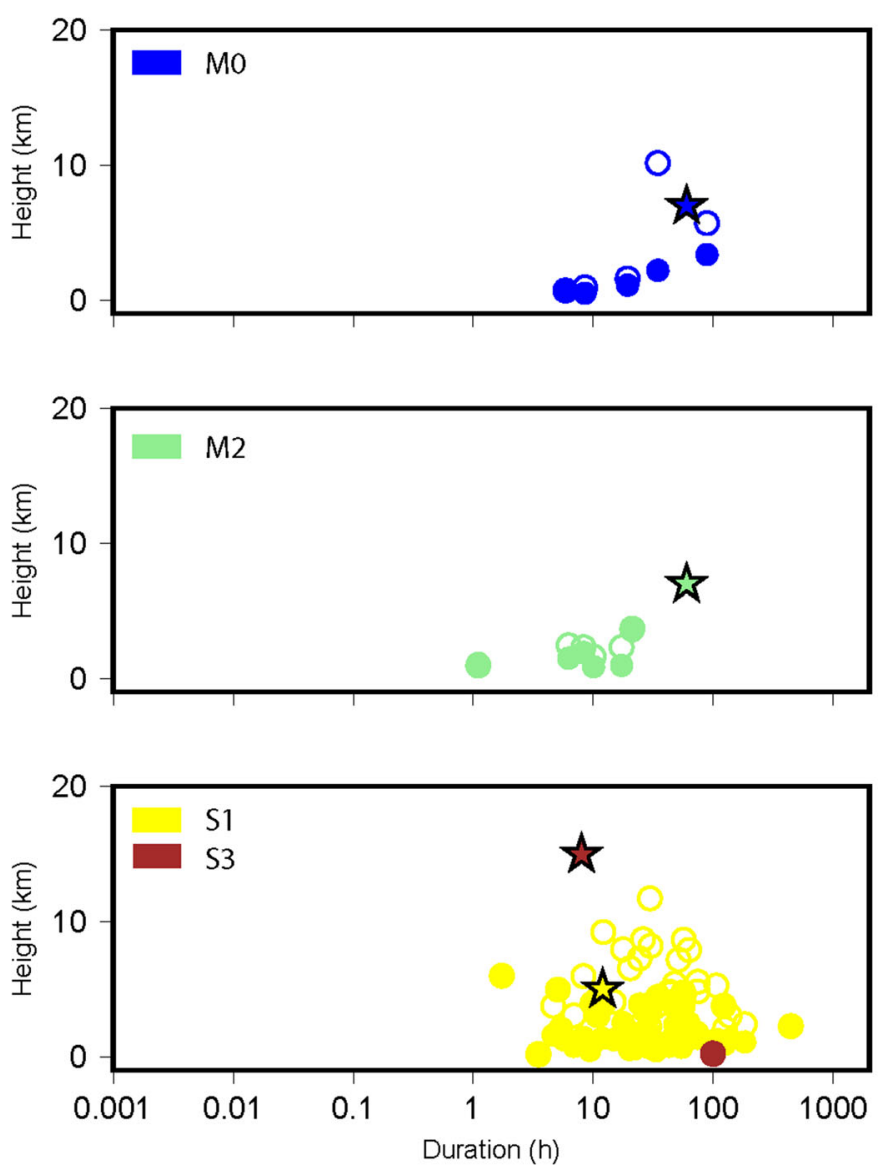

demonstrates the similarity in observed characteristics for the different volcanoes. Noting the $\log$ axis for duration, the results imply much less variation in volcanic cloud height in comparison to eruption duration. While there is a spread in the durations for the categories, there is little difference in average volcanic cloud height. This is also evident by the average of all advisories (black symbol), which displays a very similar volcanic cloud height to those of the individual categories. A majority of the data points fall at a distance from the parameters within the M-ESP database, with the parameters for M2/M0 best representing the data.

\section{Discussion}

The VAA record provides high-frequency information that complements geological and historical records of eruptive activity, and helps define activity both globally and at individual volcanoes. Information from the VAAs can be mined to assess activity at a volcano without the need for processing and in-depth data analysis and VAAs therefore provide an important resource in understanding global ash aviation hazard. Our analysis shows that some regions of airspace are affected considerably more frequently than others. We show that a majority of advisories issued in the time period considered were issued by Darwin, Tokyo, Buenos Aires,
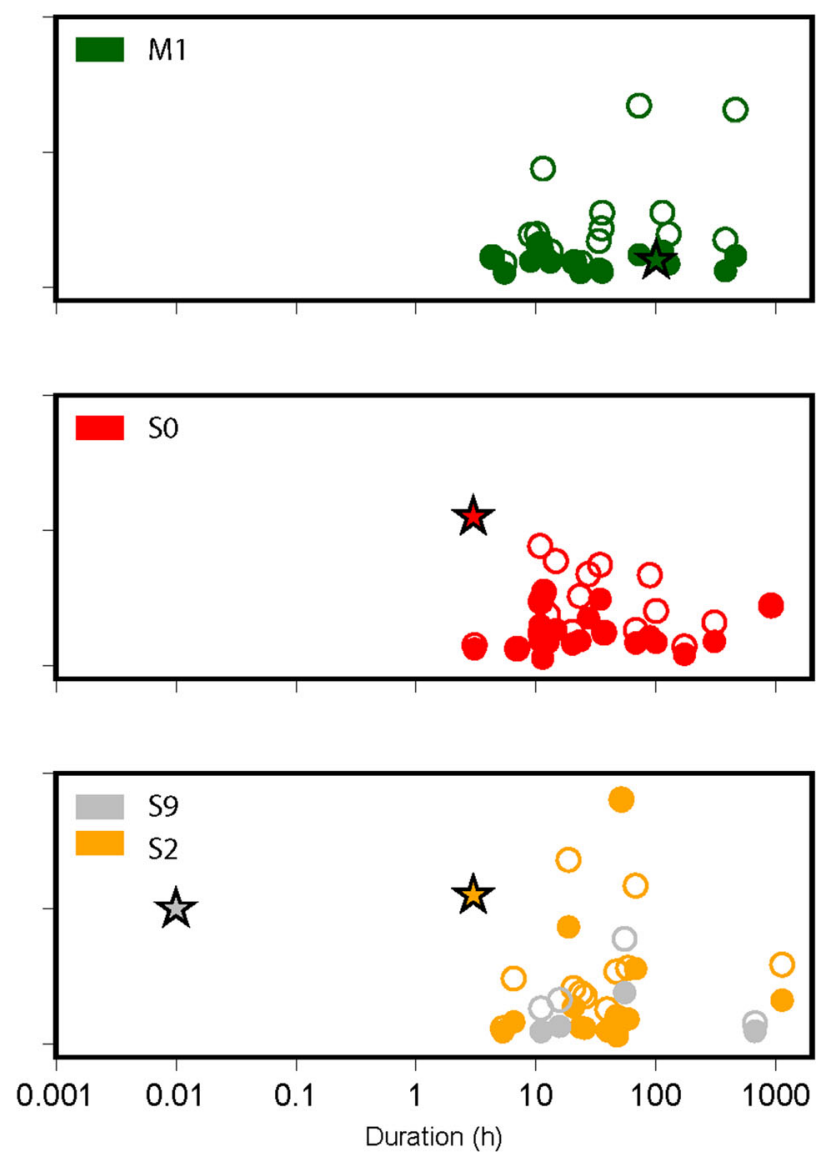

Fig. 8 Average (filled circles) and 99th percentile (open circles) VAA-defined plume height (converted to km above the vent from FL) versus average duration per volcano. Each panel represents a different M-ESP category. Stars represent the height and eruption duration assigned in the M-ESP database 


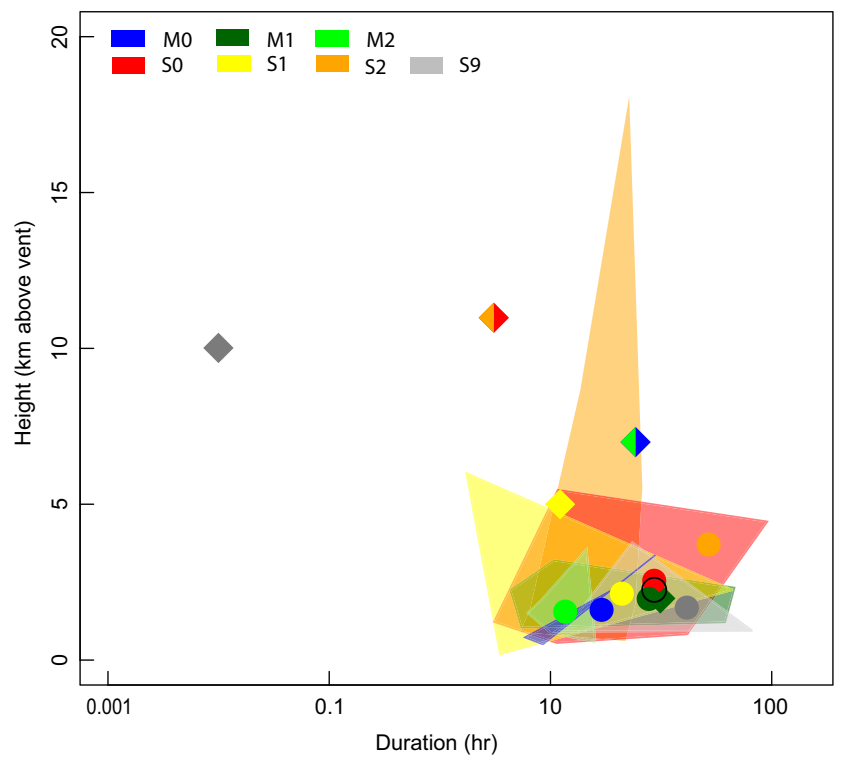

Fig. 9 Convex hulls fitted to average data of the categories within Fig. 7. Circles represent the average height and duration for volcanoes in each category, the black circle represents the average for all volcanoes, and the diamonds are the M-ESP parameters

and Washington VAACs and are related to eight volcanoes, with more than $20 \%$ related to activity at Sakurajima and Dukono volcanoes, in Japan and Indonesia respectively.

We find that, although the global amount of known explosive volcanic activity has not increased in the time period examined, the number of VAAs issued per year has increased, particularly since 2015. This increase is most apparent for volcanic ash clouds between FL101 and FL200 (3-6 km asl) and correlates in time with the advent of improved technology for detecting lower altitude and lower concentration volcanic ash clouds, over longer periods. At least three factors could be responsible for this increase: (1) changes to reporting processes, (2) improved communications between SVOs and VAACs, and (3) increased ability to detect volcanic ash with satellite-sensing techniques. Each of these factors is discussed in more detail below.

Although ICAO standards and recommended practices have not greatly changed during the period of the study, procedures within VAACs have been evolving in line with quality management processes, and collaboration on best-practice between the VAACs, as established by the International Volcanic Ash Task Force (IVATF), to ensure greater consistency of approach (IVATF Summary 2012, accessed October 2020).

Ground observations from SVOs (Pallister et al. 2019), new remote sensing capabilities and observations, and communication of these observations to VAACs have improved greatly in some areas during the period. The eruptions of Dukono (6644 advisories) or Sinabung (2218 advisories) in Indonesia, for example, have been observed extensively and recorded by webcam and photos, with regular operational reports exchanged between the Indonesian Centre for Volcanology and Geological Hazard Mitigation (a SVO) and VAAC Darwin, and a constant stream of multi-lingual 'chat' between those two centres, airlines, air traffic control, and others. New radars have also been built in many regions, and new networks for detecting volcanic lightning (McNutt and Thomas 2015; Hargie et al. 2018) and infrasound (Matoza et al. 2017) have also enabled increased detections of volcanic eruptions and ash emission.

Finally, the temporal increase in total VAAs issued roughly parallels the increase in VAAs issued on satellite-based detections (Fig. 2). The increase with time of satellite-based detection of volcanic ash is most apparent at VAACs such as Tokyo and Darwin that have both new-generation coverage since 2014 (from HIMAWARI-8) and volcanoes that frequently produce small volcanic clouds. Although this trend is less clear for VAAC Washington, the VAAC attributes the increase in total VAAs to better temporal, spectral, and spatial resolution from GOES-16. Those VAACs whose regions contain no frequently active volcanoes, such as Montreal and London, show essentially no change in the rate of VAAs with time or show step changes where steps correspond to activity at an indiviudal volcano. Those VAACs with intermediate numbers of VAAs, such as Buenos Aires, Toulouse, Wellington, and Anchorage, also show stepped curves but with steps that appear more frequent in later years and mirror step increases in satellite detection capability but also changes in eruptive activity. An abrupt increase in the rate of VAAs at VAAC Buenos Aires starting in late 2016, for example, represents the start of repeated, small explosive events at Sabancaya. Steps in the VAAC Anchorage curve in 2013 and 2017 correspond to eruptive activity at Pavlof and Bogoslof, respectively. Between these years, there is a roughly continuous issuance of VAAs for multiple volcanoes in both Alaska and Kamchatka (Sheveluch, Zupanovsky, Klyuchevskoi, Karymsky, Pavlof, and Cleveland among others). Information in the VAAs indicate that nearly all events were detected by satellite sensors, and a number represent volcanic activity within the VAAC Tokyo AoR. The more intermittent nature of advisory issuance means changes in rate of VAA issuance are less apparent for these regions.

Within this study, FL information within the VAAs was used as a proxy for eruption cloud height. Volcanic cloud heights are estimated using a variety of methods, for example through direct observation or analysis of radar or satellite imagery, each with its own uncertainties. Tupper and Wunderman (2009) compared independent daily maximum eruption height reports from ground and satellite analysis over Indonesia and Papua New Guinea from 1982 to 2005 and concluded that there were substantial differences, to the extent that the datasets are independent and cannot, without further investigation, be used to substitute for each other. Their analysis indicated that for large events, satellite observations of plume height are more reliable than ground observations, whereas for smaller events producing low-lying clouds, the opposite is true due to obscuration by clouds and poor spatial and temporal resolution of satellite imagery. With the 
higher spatial and temporal resolution of satellite instrument developments and imagery afforded by recent satellites, the reliability of using satellite imagery for detecting explosive eruptions and plume height has likely improved.

The Tupper and Wunderman (2009) example highlights the mutually beneficial relationship between VAACs and SVOs. In many cases, different and complementary plume information is available to the VAAC which is not easily observable by or accessible to SVOs. For example, during the long-term eruption at Soufrière Hills volcano, Montserrat, which began in 1995, it was not always possible for the responsible SVO (Montserrat Volcano Observatory) to visually assess heights of plumes at night-time or in the daytime due to cloud cover and/or ashfall. In such cases, the SVO reported the onset explosions to the Washington VAAC, information on plume height was provided to the SVO by the VAAC through analysis of satellite information, and the SVO was able to provide additional context, such as likely duration of explosive activity (S. Loughlin, pers. comm., August 2020).

Uncertainties on information in the VAAs is likely large than, for example, the information in the published record due to the near-real-time nature of the data. Uncertainty in volcanic cloud heights from satellite sensors depends on methodology but is commonly $\pm 20 \%$ (e.g. Mackie et al. 2014; Pavolonis et al. 2013; Tupper and Wunderman 2009). Uncertainty in radar-derived heights is frequently $\pm 1 \mathrm{~km}$ even in good conditions (Arason et al. 2011). Given the differences between the VAA mean height and Mastin et al. (2009) height (Table 4) are commonly greater than $50 \%$, these uncertainties cannot explain the differences in height between these datasets. When comparing cloud height data with the information in the M-ESP database, it is worthwhile noting that the M-ESP database does not account for variation in atmospheric conditions from polar to equatorial regions. For a given eruption rate, an eruption in the tropics will produce a higher volcanic ash cloud than in polar regions. This could account for some of the disparity between the observed volcanic ash cloud height and that given in the M-ESP database. However, given that a majority of the events analysed in this study occur in lower rather than higher latitudes (Fig. 2), it is not anticipated that volcano latitude has a great impact on the results.

Uncertainties in eruption duration could be higher than those for cloud heights, given that duration here reflects how long ash remains in the atmosphere, rather than the duration of emission from the vent (Fig. 9). Despite this difference, the MESP duration fits that estimated from the VAAs remarkably well, perhaps due to overestimation in the M-ESP database source term. Both height and duration are likely to be more uncertain when there is no SVO and therefore no direct observation of volcanic activity, highlighting the importance of strong, well-functioning SVOs and also the timely communication between SVO and VAAC.
The increase in VAAs with time related to improved observations complicates the use of the VAAs for assessing global or volcano-scale rates of activity. Our analysis indicates that the number of low-level plumes observed has increased since 2015. However, this does not mean that these plumes were not present before, but rather that they were not detected or reported on. Such data limitations pertaining to the availability of observations, and in particular related to the scale of an eruption, are common in databases describing the volcanic activity. Uncertainties in the geological record are well known (Rougier et al. 2018); deposits of large eruptions are better preserved and studied compared to those from smaller eruptions. As observational capability has improved, the number of smaller eruptions in the geological record increases towards the present day. Even in the historical record, larger eruptions are better described than smaller eruptions because their impact is greater and descriptive stories last longer, passed down by oral traditions (e.g. the 79 AD eruption of Vesuvius (Sigurdsson et al. 2006), the 1783-1784 eruption of Laki (Thordarson 2003), and the 1883 eruption of Krakatau (Verbeek 1885; Simkin and Fiske 1983)). The VAA record, as with other databases, presents a record of explosive volcanic activity of increasing temporal resolution with time.

Our study illustrates how the VAA record can complement more conventional data sources used in databases of the M-ESP and the Smithsonian Institution GVP, which rely on SVO reports and published journal articles. Publications are more numerous for larger events, whereas those events that produce the clouds detailed in SVO reports and described in most VAAs may be smaller and less likely to be documented in peer-reviewed papers. This difference is exacerbated by improved technology that detect ever smaller volcanic ash clouds. This difference is highlighted in Fig. 7 where the volcanic ash cloud height per volcano proposed in the Mastin et al. (2009a) database is systematically higher than that documented in the VAAs. This difference speaks to a greater issue relating to data and the volcanic record. Necessarily, data describing many past eruptions are based on ground observations and analysis of the resultant deposits. Near-real-time information, such as that presented in VAAs, provides insight into events that would not normally be recorded by deposits, or even SVO reports in some circumstances, and therefore extends understanding of global explosive volcanism, capturing not only the very largest events but also more frequent lowlevel activity. Such insight, along with information on deposit and observation information, aids understanding of the range of explosive behaviour at a volcano and enables a better definition of ESPs.

When analysed on a volcano-by-volcano basis (Fig. 8), the M-ESP-assigned volcanic ash cloud heights fall close to but 
above the 99th percentile of observed cloud characteristics described within the VAAs, showing that on a broad level, the categories within the M-ESP database represent the upper limit in volcanic activity expected for volcanoes within these categories (Fig. 9). The parameters fit particularly well for the M1 and $\mathrm{S} 1$ categories. Notable exceptions are volcanoes in categories M0 and S0, for which there is little historical information to aid assignment of parameters, and an eruption of a medium size is assumed. The M0 and S0 categories describe volcanoes of a number of types, with a range in eruptive styles and geochemistry. The results indicate that a better way to categorise poorly known or monitored volcanoes is required. In this context, the likelihood of a 'medium-sized' eruption based on published accounts is overestimated. The results for the M2 and S2 categories imply that parameters defined through analysis of the geological record represent larger, rarer events, rather than more frequent smaller eruptions. This results in these volcanoes being given high to mid-range hazard scenarios where a lower range eruption scenario might be more appropriate.

Our results imply that it may be more appropriate to assign categories a smaller scale eruption scenario with volcanic ash cloud heights of $2 \mathrm{~km}$ above the vent, where little is known about an eruption or volcano, and to update as more information becomes available. Users of the M-ESP database who are setting up operational forecasts will have to assess whether to use source parameters that reflect most likely, or larger, eruption scenarios. SVOs may be able to help with such decision-making.

\section{Conclusions}

VAAs provide information that informs the global risk of volcanic ash to civil aviation in near-real-time. As an operational product, these advisories have not previously been analysed outside of this remit and therefore are a currently underused resource on volcanic behaviour with huge potential for insight into volcanic activity on a global scale. The number of VAAs issued with time can be used as a measure of the rate of volcanic activity if other influences on the record, such as increased ability to recognise volcanic ash clouds due to advances in satellite sensor capabilities and coverage and increased reporting, are also considered. The VAAs present a novel dataset, containing information on frequency, duration, and volcanic cloud height of eruptions over the past few decades. This information enables the analysis of the characteristics of activity at those volcanoes that impact airspace and allows a move towards a better understanding of global ash aviation hazard. A review of VAAs issued between 1 January 2009 and 1 January 2019 shows that eight volcanoes (from a total of 139 with advisories during this period) are responsible for $50 \%$ of the more than 57,000 advisory issues during this time. An increase in the number of VAAs issued over time is attributed to the improved ability to observe ash at lower atmospheric levels rather than an increase in the frequency of eruptions. The analysis of FL information extracted from the VAAs shows that a large majority of reported plumes are at of relatively low level $(\sim 2 \mathrm{~km}$ above the vent), considerably lower than the assigned parameters in the Mastin et al. (2009a) ESP database. We therefore propose that where no other height information is available, a cloud height of $2 \mathrm{~km}$ above vent may constitute a reasonable most likely cloud height for ash hazard modelling purposes.

Acknowledgements This work has significantly benefitted from the insight and reports provided by the VAACs. We would specifically like to thank Dov Bensimon, Marcel Roux, Soledad Osores, Jeff Osiensky, Yuichi Imamura, Jarrad Denman, Mark Seltzer, Anton Muscat, and Philippe Hereil for their contribution of data and insight and for reviewing an early version of the manuscript. We are grateful for helpful discussions with Matt Hort and for an initial review of the manuscript by D Schneider and S Loughlin. We thank S Barsotti for a thorough review and the Editor, Christopher Gregg, for providing numerous helpful comments on the final manuscript. SLE was funded by the Global Geological Risk Research Platform of the British Geological Survey NC-ODA grant NE/ R000069/1: Geoscience for Sustainable Futures and publishes with permission of the CEO, British Geological Survey.

\section{Appendix}

Table 5 List of acronyms

\begin{tabular}{ll}
\hline AoR & Area of responsibility \\
ASL & Above sea level \\
ESP & Eruption source parameter \\
FL & Flight level \\
GVP & Global Volcanism Program \\
ICAO & International Civil Aviation Organization \\
IVATF & International Volcanic Ash Task Force \\
IAVW & International Airways Volcano Watch \\
LaMEVE & Large Magnitude Explosive Volcanic Eruption \\
M-ESP & Mastin et al. (2009a) Eruption Source Parameter \\
MWO & Meteorological Watch Offices \\
NWP & Numerical Weather Prediction \\
SACS & Support to Aviation Control Service \\
SIGMET & Significant Meteorological Information \\
SVO & State Volcano Observatory \\
VAA & Volcanic Ash Advisories \\
VAAC & Volcanic Ash Advisory Centre \\
VAG & Volcanic Ash Graphic \\
VEI & Volcanic Explosivity Index \\
VOLCAT & VOLcanic Cloud Analysis Toolkit \\
VONA & Volcanic Observatory Notice for Aviation \\
\hline
\end{tabular}


Open Access This article is licensed under a Creative Commons Attribution 4.0 International License, which permits use, sharing, adaptation, distribution and reproduction in any medium or format, as long as you give appropriate credit to the original author(s) and the source, provide a link to the Creative Commons licence, and indicate if changes were made. The images or other third party material in this article are included in the article's Creative Commons licence, unless indicated otherwise in a credit line to the material. If material is not included in the article's Creative Commons licence and your intended use is not permitted by statutory regulation or exceeds the permitted use, you will need to obtain permission directly from the copyright holder. To view a copy of this licence, visit http://creativecommons.org/licenses/by/4.0/.

\section{References}

Arason P, Peterson GN, Bjornsson H (2011) Observations of the altitude of the volcanic plume during the eruption of Eyjafjallajökull, AprilMay 2010. Earth Syst Sc Data 3:9-17. https://doi.org/10.5194/ ESSD-3-9-2011

Bessho K, Date K, Hayashi M, Ikeda A, Imai T, Inoue H, Kumagai Y, Miyakawa T, Murata H, Ohno T, Okuyama A $(2016,2016)$ An introduction to Himawari-8/9 - Japan's new-generation geostationary meteorological satellites. J Meteorol Soc Japan, Ser II. https:// doi.org/10.2151/jmsj.2016-009

Brenot H, Theys N, Clarisse L, van Geffen J, van Gent J, Van Roozendael M, van der A R, Hurtmans D, Coheur PF, Clerbaux C, Valks P, Hedelt P, Prata F, Rasson O, Sievers K, Zehner C (2014) Support to Aviation Control Service (SACS): an online service for near-realtime satellite monitoring of volcanic plumes. Nat Hazards Earth Syst Sci 14:1099-1123. https://doi.org/10.5194/nhess-14-1099-2014

Brown SK, Loughlin SC, Sparks RSJ, Vye-Brown C, Barclay J, Calder E, Cottrell E, Jolly G, Komorowski JC, Mandeville C, Newhall C (2015) Global volcanic hazard and risk. In: Loughlin SC, Sparks S, Brown SK, Jenkins SF, Vye-Brown C (eds) Global volcanic hazards and risk. Cambridge University Press, Cambridge, pp 81-172

Collini E, Osores MS, Folch A, Viramonte JG, Villarosa G, Salmuni G (2013) Volcanic ash forecast during the June 2011 Cordón Caulle eruption. Nat Hazards 66:389-412. https://doi.org/10.1007/s11069012-0492-y

Crosweller HS, Arora B, Brown SK, Cottrell E, Deligne NI, Guerrero NO, Venzke E (2012) Global database on large magnitude explosive volcanic eruptions (LaMEVE). J Appl Volcanol 1. https://doi.org/ 10.1186/2191-5040-1-4

Global Volcanism Program (2013) Volcanoes of the world, v. 4.8.0. (E. Venzke, Ed.). Smithsonian Institution. Downloaded 29 January 2019. https://doi.org/10.5479/si.GVP.VOTW4-2013

GOES-R Program/ Code 410 (2020) 410-R-CONOPS-0008 Version 3.0. GOES-R Series Concept of Operations (CONOPS), U.S. Dept of Commerce, National Oceanic and Atmospheric Administration, NOAA Satellite and Information Service, National Aeronautics and Space Administration https://www.goes-r.gov/syseng/docs/ CONOPS.pdf

Guffanti M, Tupper A (2015) Volcanic ash hazards and aviation risk. In: Papale P (ed) Volcanic hazards, risks and disasters. Elsevier, Amsterdam, pp 87-108

Guffanti M, Ewert JW, Gallina GM, Bluth GJ, Swanson GL (2005) Volcanic-ash hazard to aviation during the 2003-2004 eruptive activity of Anatahan volcano. Commonwealth Northern Mariana Islands J Volcanol Geotherm Res 146:241-255. https://doi.org/10. 1016/j.jvolgeores.2004.12.011

Guffanti M, Mayberry GC, Casadevall TJ, Wunderman R (2008) Compilation of disruptions to airports from volcanic activity (version 1.0, 1944-2006): U.S. Geological Survey Open-File Report 2007-1256, 31 p. Available online at https://pubs.usgs.gov/ of/2007/1256/

Hargie KA, Van Eaton AR, Mastin LG, Holzworth RH, Ewert JW, Pavolonis M (2018) Globally detected volcanic lightning and umbrella dynamics during the 2014 eruption of Kelud, Indonesia. J Volcanol 382:81-91. https://doi.org/10.1016/j.jvolgeores.2018.10. 016

International Civil Aviation Organization (2004) Doc 9766-AN/968, Handbook on the International Airways Volcano Watch (IAVW): operational procedures and contact list https://www.icao.int/ airnavigation/METP/MOGVA\%20Reference\%20Documents/ Handbook\%20on\%20the\%20IAVW,\%20Doc\%209766.pdf. Accessed Jan 2020

International Civil Aviation Organization (2012) Summary of the accomplishments of the International Volcanic Ash Task Force (IVATF) https://www.icao.int/safety/meteorology/ivatf/Documents/IVATF. Summary.of.Accomplishments.pdf. accessed Oct 2020

Jenkins SF, Magill CR, McAneney KJ (2007) Multi-stage volcanic events: a statistical investigation. J Volcanol Geotherm 161:275288. https://doi.org/10.1016/j.jvolgeores.2006.12.005

Jenkins SF, Magill C, McAneney J, Blong R (2012) Regional ash fall hazard I: a probabilistic assessment methodology. B Volcanol 74: 1699-1712. https://doi.org/10.1007/s00445-012-0627-8

Lechner P, Mackersy K, Tupper A, Patrick R, Ruglys M, Guffanti M, Romero, R (2009). Guidance for state volcano observatories: the International Airways Volcano Watch. $1^{\text {st }}$ Edition, http://www. wovo.org/assets/docs/gvo2009s.pdfaccessed Jan 2020

Lechner P, Tupper A, Guffanti M, Loughlin S, Casadevall T (2017) Volcanic ash and aviation - the challenges of real-time, global communication of a natural hazard. In: Fearnly C, Bird DK, Haynes K, McGuire W, Jolly G (eds) Observing the volcano world: volcano crisis communication. Springer, Cham, pp 51-64. https://doi.org/10. 1007/11157_2016_49

Mackie S, Millington S, Watson IM (2014) How assumed composition affects the interpretation of satellite observations of volcanic ash. Meteorol Appl 21:20-29. https://doi.org/10.1002/met.1445

Mahony SH, Sparks RSJ, Wallace LM, Engwell SL, Scourse EM, Barnard NH, Kandlbauer J, Brown SK (2016) Increased rates of large-magnitude explosive eruptions in Japan in the late Neogene and Quaternary. Geochem Geophys Geosyst 17:2467-2479. https:// doi.org/10.1002/2016GC006362

Mastin LG, Guffanti M, Servranckx R, Webley P, Barsotti S, Dean K, Durant A, Ewert JW, Neri A, Rose WI, Schneider D, Siebert L, Stunder B, Swanson G, Tupper A, Volentik A, Waythomas CF (2009a) A multidisciplinary effort to assign realistic source parameters to models of volcanic ash-cloud transport and dispersion during eruptions. J Volcanol Geotherm 186:10-21. https://doi.org/10. 1016/j.jvolgeores.2009.01.008

Mastin LG, Guffanti M, Ewert JW, Spiegel J (2009b) Preliminary spreadsheet of eruption source parameters for volcanoes of the world. US Geol Surv Report 2009-1133:V1.2

Matoza RS, Green DN, Le Pichon A, Shearer PM, Fee D, Mialle P, Ceranna L (2017) Automated detection and cataloging of global explosive volcanism using the International Monitoring System infrasound network. J Geophys Res Solid Earth 122:2946-2971. https://doi.org/10.1002/2016JB013356

McNutt SR, Thomas RJ (2015) Volcanic lightning. In: Sigurdsson H, Houghton B, McNutt S, Rymer H, Stix J (eds) The encyclopedia of volcanoes, 2nd edn. Academic Press, London, pp 1059-1067

Naismith AK, Watson IM, Escobar-Wolf R, Chigna G, Thomas H, Coppola D, Chun C (2019) Eruption frequency patterns through time for the current (1999-2018) activity cycle at Volcán de Fuego derived from remote sensing data: evidence for an accelerating cycle of explosive paroxysms and potential implications of 
eruptive activity. J Volcanol Geotherm 371:206-219. https://oi. org/10.1016/j.jvolgeores.2019.01.001

Neal CA, McGimsey RG, Gardner CA, Harbin ML, Nye CJ (1995) Tephra-fall deposits from the 1992 eruptions of Crater Peak, Mount Spurr, Alaska. In: Keith TE (ed) The 1992 eruptions of Crater Peak, Mount Spurr, Alaska, US Geol Surv Bulletin 2139: 65-79. US Geol Surv, Washington DC

Pallister J, Wessels R, Griswold J, McCausland W, Kartadinata N, Gunawan, Budianto H, Primulyana S (2018) Monitoring, forecasting collapse events, and mapping pyroclastic deposits at Sinabung volcano with satellite imagery. J Volcanol Geotherm 382:149-163. https://doi.org/10.1016/j.jvolgeores.2018.05.012

Pallister J, Papale P, Eichelberger J, Newhall C, Mandeville C, Nakada S, Marzocchi W, Loughlin S, Jolly G, Ewert J, Selva J (2019) Volcano observatory best practices (VOBP) workshops-a summary of findings and best-practice recommendations. J Appl Volcanol 8. https:// doi.org/10.1186/s13617-019-0082-8

Pavolonis MJ, Heidinger AK, Sieglaff J (2013) Automated retrievals of volcanic ash and dust cloud properties from upwelling infrared measurements. J Geophys Res Atmos 118:1436-1458. https://doi.org/ 10.1002/jgrd.50173

Pavolonis MJ, Sieglaff J, Cintineo J (2018) Automated detection of explosive volcanic eruptions using satellite-derived cloud vertical growth rates. Earth Space Sci 5:903-928. https://doi.org/10.1029/ 2018ea000410

Prata AJ (1989a) Infrared radiative transfer calculations for volcanic ash clouds. Geophys Res Lett 16:1293-1296. https://doi.org/10.1029/ GL016i011p01293

Prata AJ (1989b) Observations of volcanic ash clouds in the 10-12 $\mu \mathrm{m}$ window using AVHRR/2 data. Int J Remote Sens 10:751-761. https://doi.org/10.1080/01431168908903916
Pyle DM (1989) The thickness, volume and grain size of tephra fall deposits. B Volcanol 51:1-15. https://doi.org/10.1007/BF01086757

Rougier J, Sparks RSJ, Cashman KV (2018) Regional and global underrecording of large explosive eruptions in the last 1000 years. J Appl Volcanol 7. https://doi.org/10.1186/s13617-017-0070-9

Sheldrake T, Caricchi L (2017) Regional variability in the frequency and magnitude of large explosive volcanic eruptions. Geology. 45:111114. https://doi.org/10.1130/G38372.1

Siebert L, Simkin T and Kimberly P, 2010. Volcanoes of the World, 3rd ed. Berkeley: University of California Press, 568 p.

Siebert L, Cottrell E, Venzke E, Andrews B (2015) Earth's volcanoes and their eruptions: an overview. In: Sigurdsson H, Houghton B, McNutt S, Rymer H, Stix J (eds) The encyclopedia of volcanoes, 2nd edn. Academic Press, London, pp 239-255

Sigurdsson H, Cashdollar S, Sparks RSJ (2006) The eruption of Vesuvius in A. D. 79: reconstruction from historical and volcanological evidence. Am J Archeol. https://doi.org/10.2307/504292

Simkin T, Fiske R (1983) Krakatau 1883: the volcanic eruption and its effects. Smithsonian Institute Press, Washington, pp 1-464

Sparks RSJ, Bursik MI, Carey S, Gilbert JS, Glaze LS, Sigurdsson H, Woods AW (1997) Volcanic plumes. John Wiley, New York, pp 1559

Thordarson T (2003) Atmospheric and environmental effects of the 1783-1784 Laki eruption: a review and reassessment. J Geophys Res Atmos. https://doi.org/10.1029/2001JD002042

Tupper A, Wunderman R (2009) Reducing discrepancies in ground and satellite-observed eruption heights. J Volcanol Geotherm 186:2231. https://doi.org/10.1016/j.jvolgeores.2009.02.015

Verbeek RDM (1885) Krakatau. Govt Press, Batavia, pp 1-495

Walker GPL (1973) Explosive volcanic eruptions: a new classification scheme. Geol Rundsch 62:431-446. https://doi.org/10.1007/ BF01840108 